BMJ Open

Sport \&

Exercise

Medicine

\section{Past and projected temporal trends in arthroscopic hip surgery in England between 2002 and 2013}

To cite: Palmer AJR Malak TT, Broomfield J, et al. Past and projected temporal trends in arthroscopic hip surgery in England between 2002 and 2013. BMJ Open Sport Exerc Med 2016;2: e000082. doi:10.1136/ bmjsem-2015-000082

- Prepublication history and additional material is available. To view please visit the journal (http://dx.doi.org/ 10.1136/bmjsem-2015000082).

Received 7 November 2015 Revised 23 December 2015 Accepted 1 January 2016

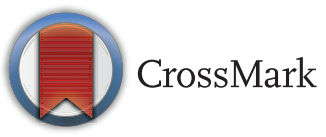

\footnotetext{
${ }^{1}$ Nuffield Department of Orthopaedics, Rheumatology and Musculoskeletal Sciences, University of Oxford, Oxford, UK ${ }^{2}$ Royal Berkshire Hospital NHS Trust, Reading, UK ${ }^{3}$ Centre for Statistics in Medicine, University of Oxford, Oxford, UK ${ }^{4}$ Public Health England, Oxford, UK
}

Correspondence to A J R Palmer; antony. palmer@ndorms.ox.ac.uk

\section{ABSTRACT}

Introduction: Hip arthroscopy is increasingly adopted for the treatment of intra-articular and extra-articular pathologies. Studies from USA demonstrate a $365 \%$ increase in the number of procedures performed between 2004 and 2009 and 250\% increase between 2007 and 2011. There is limited evidence of long-term efficacy for this procedure and hip arthroscopy is not universally funded across England. The aim of this study is to describe temporal trends in the adoption of hip arthroscopy in England between 2002 and 2013 and to forecast trends for the next 10 years.

Methods: A search of the Hospital Episodes Database was performed for all codes describing arthroscopic hip procedures with patient age, sex and area of residence.

Results: 11329 hip arthroscopies were performed in National Health Service hospitals in England between 2002 and 2013. The number of hip arthroscopies performed increased by $727 \%(p<0.0001)$ during this period and is forecast to increase by $1388 \%$ in 2023 . Females represent $60 \%$ of all patients undergoing hip arthroscopy $(p<0.001)$. Median age category is $40-44$ for females and 35-39 for males and average age decreased during the study period $(p<0.0001)$. There is significant regional variation in procedure incidence. In the final year of this study the highest incidence was in the Southwest (8.63/100 000 population) and lowest in East Midlands (1.29/100 000 population).

Conclusions: The increase in number of hip arthroscopies performed in England reflects trends in USA and continued increases are forecast. Evidence from robust clinical trials is required to justify the increasing number of procedures performed and regional variation suggests potential inequality in the provision of this intervention.

\section{INTRODUCTION}

Arthroscopic intervention is adopted for an increasing number of hip pathologies. In an acute setting, joint irrigation can be performed arthroscopically for the management of septic arthritis. ${ }^{1}$ Fixation of femoral head fractures is also possible arthroscopically. ${ }^{2}$ In

\section{What are the new findings?}

Our study demonstrates a $727 \%$ increase in the number of arthroscopic hip procedures performed in England between 2002 and 2013 and a forecast increase of $1388 \%$ by 2023 , despite limited evidence of long-term efficacy. Hip arthroscopy is most commonly performed in females and average patient age is decreasing. There is significant regional variation with a 6.69 -fold difference in procedure incidence between regions suggesting potential inequality in healthcare provision.

How might it impact on clinical practice in the near future?

The increasing number of arthroscopic hip procedures performed each year in England highlights the requirement for robust evidence of procedurespecific effectiveness from clinical trials. Large regional variation in the provision of hip arthroscopy suggests uncertainty among clinicians and healthcare commissioners over clinical effectiveness. The decreasing age of patients is consistent with cohort studies demonstrating good outcomes in active young adults and worse outcomes with advancing age.

an elective setting, hip arthroscopy is used in the treatment of a range of intracapsular conditions including femoroacetabular impingement (FAI), ${ }^{3}$ labral pathology, ${ }^{4}$ chondral lesions, ${ }^{5}$ instability, ${ }^{6}$ synovial chondromatosis $^{7}$ and ligamentum teres injuries. ${ }^{8}$ Applications continue to expand and hip arthroscopy is also used to facilitate hip reduction in infants with development dysplasia of the hip ${ }^{9}$ and for the treatment of extracapsular pathology including iliopsoas tendon and iliotibial band pathology. ${ }^{10}$

Hip arthroscopy was first described in $1931,{ }^{11}$ although implementation has only been possible more recently after technical 
advances were made that allow adequate distraction of the femoral head from the acetabulum and joint instrumentation with arthroscopic devices. ${ }^{12}$ The arthroscopic approach confers potential benefits over open surgery and most studies report lower complication rates and outcomes that are equal to or better than open approaches. ${ }^{13}$

An increasing number of arthroscopic hip procedures are performed each year worldwide. In Korea, there was a twofold increase between 2007 and $2010 .{ }^{14}$ In the USA there was an increase of $365 \%$ between 2004 and $2009^{15}$ and $250 \%$ between 2007 and $2011,{ }^{16}$ where an estimated 70000 procedures are performed annually. ${ }^{17}$ The number of hip arthroscopy procedures performed by orthopaedic trainees in the USA increased 18-fold between 1999 and 2009. ${ }^{11}$ Despite the rapid uptake, there are very few studies reporting long-term outcomes for arthroscopic hip surgery and these are limited to cohort studies. This is particularly salient given the increasing questions raised over the efficacy of arthroscopic knee surgery. ${ }^{18}$ Randomised controlled trials are required to compare the efficacy of arthroscopic hip surgery with non-operative interventions, ${ }^{19}$ and such studies are currently recruiting patients. ${ }^{20}$

The adoption of hip arthroscopy in the UK has not been described. It is not universally funded by Clinical Commissioning Groups, which may give rise to geographical variation in practice. The aim of this study is to describe temporal trends in the adoption of hip arthroscopy since 2002 and to project trends for the next 10 years. The publication of temporal trends may aid decision-making by surgeons and commissioning bodies. Regional variation is of particular interest given the perceived inequalities in the commissioning landscape.

\section{METHODS}

Data was collected from the Hospital Episode Statistics (HES) database. ${ }^{21}$ The HES database contains data on patients attending National Health Service (NHS) hospitals in England for treatment. Each entry represents a single episode of care and codes are assigned to diagnoses and procedures during that episode. Anonymised data was requested using Operating Procedure Codes (OPCS-4) specific to hip arthroscopy and included patient age and gender and area of residence between the years 2002 and 2013. The search included all arthroscopic procedures that were combined with joint-specific codes for the hip (see online supplementary data for full search details). The generic nature of these codes and their modification through different iterations of OPCS-4 codes within the period of this search meant it was not possible to analyse trends in individual procedures. Several procedures may be performed within the same joint during arthroscopic hip surgery, for example, chondroplasty and labral repair. When several codes were encountered within the same patient episode, only the primary code was counted to prevent duplication. To aid data analysis, the Health and Social Care Information Centre geographical regions in England were grouped as the North (North East (q30), North West (q31), Yorkshire and the Humber (q32)), Midlands (East Midlands (q33), West Midlands (q34), East of England (q35)), South East (South East Coast (q37), South Central (q38)), South West (q39) and London (q36). The number of procedures performed in each region was calculated per 100000 population. Projections were made using the Drift method and are provided with $95 \%$ prediction intervals. Forecasts are equal to the last value plus the average change seen in historical data, so that the forecast for time $\mathrm{T}+\mathrm{h}$ is given by:

$$
\hat{\mathrm{y}}_{\mathrm{n}+\mathrm{h} \mid \mathrm{n}}=\mathrm{y}_{\mathrm{n}}+\frac{\mathrm{h}}{\mathrm{n}-1}\left(\mathrm{y}_{\mathrm{n}}-\mathrm{y}_{1}\right) .
$$

All statistical tests were performed using STATA V.13.1 (StataCorp, College Station, Texas, USA). Relationships between variables were explored using a $\chi^{2}$ test. Statistical analysis of trends was performed using simple linear regression for continuous variables and Wilcoxon Rank-Sum methodology for categorical variables. A $p$ value less than 0.05 was taken as the threshold for significance.

\section{RESULTS}

Total number of procedures

A total of 11329 hip arthroscopies were performed in NHS hospitals in England between 2002 and 2013. There was a statistically significant increase of $727 \%$

Table 1 Observed and forecast total number of hip arthroscopies (with $95 \%$ prediction intervals (PI))

\begin{tabular}{lcl}
\hline & Total number & \\
\cline { 2 - 3 } Year & Observed & Forecast (95\% PI) \\
\hline 2002 & 257 & - \\
2003 & 300 & - \\
2004 & 357 & - \\
2005 & 441 & - \\
2006 & 575 & - \\
2007 & 585 & - \\
2008 & 815 & - \\
2009 & 1070 & - \\
2010 & 1449 & - \\
2011 & 1601 & - \\
2012 & 1754 & - \\
2013 & 2125 & - \\
2014 & - & $2295(2037,2553)$ \\
2015 & - & $2465(2085,2844)$ \\
2016 & - & $2634(2152,3117)$ \\
2017 & - & $2804(2228,3381)$ \\
2018 & - & $2974(2308,3640)$ \\
2019 & - & $3144(2392,3896)$ \\
2020 & - & $3318(2478,4149)$ \\
2021 & - & $3484(2566,4401)$ \\
2022 & - & $3653(2655,4652)$ \\
2023 & - & $3823(2744,4092)$ \\
\hline & &
\end{tabular}




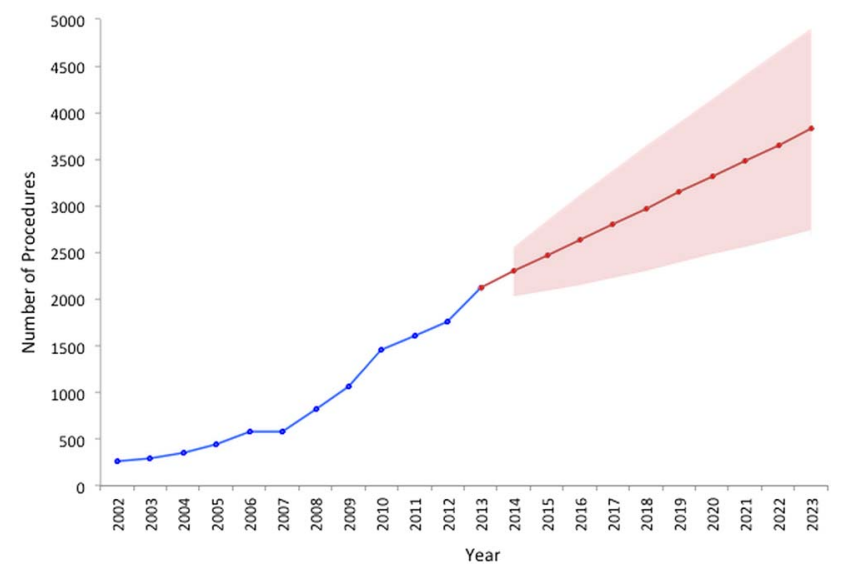

Figure 1 Observed and forecast total number of hip arthroscopies (with 95\% prediction intervals).

$(\mathrm{p}<0.0001)$ during this period and there is a projected increase of $1388 \%$ by 2023 (table 1 and figure 1).

\section{Patient demographics}

Arthroscopic hip procedures are performed more frequently in females $(60.3 \%)$ than males $(39.7 \%)$ $(\mathrm{p}<0.001$; table 2 and figure 2$)$. Females accounted for between $56.3 \%$ and $64.1 \%$ of cases throughout all years of the study and there was no statistically significant change in these proportions with time $(p=0.289$; table 2$)$.

Females were older at the time of surgery with a median age range 40-44 years compared with 35-39 for males (table 2) although this was not statistically significant $(p=0.075)$. The age of patients undergoing surgery is decreasing $(\mathrm{p}<0.0001 \mathrm{z}=-0.544)$ and this trend is present for males $(\mathrm{p}<0.0001 \mathrm{z}=-3.96)$ and females $(\mathrm{p}<0.0001 \mathrm{z}=-3.83)$. The age group with the greatest increase in procedure rate is $20-24$ years.

\section{Regional variation}

There has been a statistically significant increase in the number of arthroscopic hip procedures performed in all

Table 2 Observed number of hip arthroscopies for males and females

\begin{tabular}{llllll}
\hline Year & Female & $\begin{array}{l}\text { Median } \\
\text { age }\end{array}$ & $\begin{array}{l}\text { Male } \\
\text { age }\end{array}$ & $\begin{array}{l}\text { Ratio } \\
\text { female: } \\
\text { male }\end{array}$ \\
\hline 2002 & 154 & & 103 & & 1.50 \\
2003 & 169 & $40-44$ & 131 & $40-44$ & 1.29 \\
2004 & 210 & & 147 & & 1.43 \\
2005 & 253 & & 188 & & 1.35 \\
2006 & 342 & & 233 & & 1.47 \\
2007 & 375 & & 210 & $35-39$ & 1.79 \\
2008 & 511 & $40-44$ & 304 & & 1.68 \\
2009 & 629 & & 441 & & 1.42 \\
2010 & 861 & & 588 & & 1.46 \\
2011 & 968 & & 633 & $35-39$ & 1.53 \\
2012 & 1079 & $40-44$ & 675 & & 1.60 \\
2013 & 1272 & & 853 & & 1.49 \\
\hline
\end{tabular}

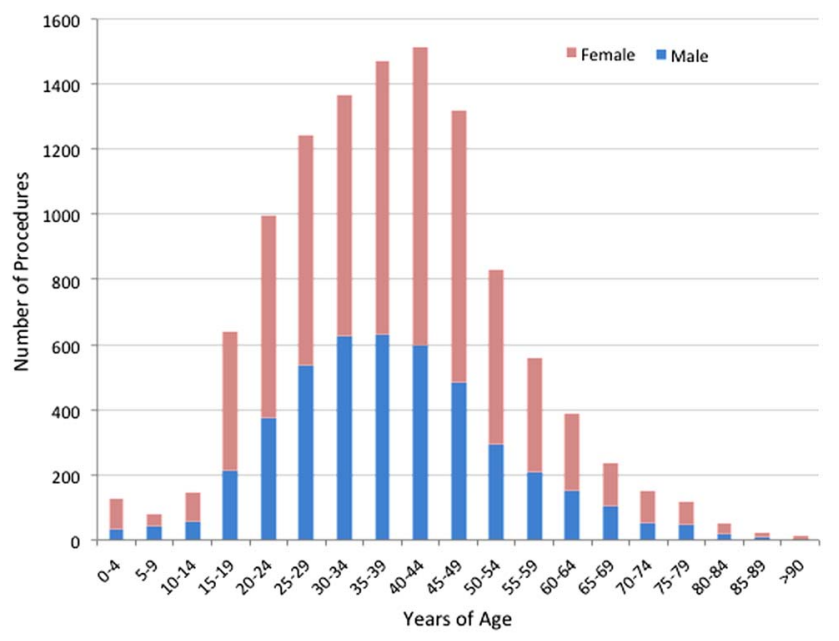

Figure 2 Histogram illustrating number of arthroscopic hip procedures 2002-2013 by age and sex.

regions of England since $2002(\mathrm{p}<0.0001)$ with a concurrent change in the relative number of procedures performed between regions $(\mathrm{p}<0.0001)$ trending towards the Southwest and Southeast (table 3). Nationwide, the incidence of hip arthroscopy procedures has risen from 0.51 to 4.09 per 100000 population (table 3 ). The greatest growth has taken place in the Southwest $(1640 \%)$ and the smallest in the Midlands (355\%). Considering all regions, the most rapid rate of increase took place between 2006 and 2009, beyond which there has been continued divergence in the number of procedures performed per capita in each region (figure 3). An increase in the number of procedures continues in the Southwest, Southeast and North of England, whereas there is evidence of plateau in the Midlands and London (figure 3). In the final year of this study, the highest number of procedures per capita was performed in the Southwest (8.63 per 100000 population) and lowest in the East Midlands (1.29 per 100000 population) Strategic Health Authority Region (figure 4). This represents a 6.69-fold difference between regions.

\section{DISCUSSION}

The aim of this study was to describe temporal trends in the adoption of hip arthroscopy since 2002 and to project trends for the next 10 years. The number of arthroscopic hip procedures performed in England has risen by $727 \%$ since 2002 and this trend is projected to continue over the next 10 years despite limited evidence of long-term efficacy or superiority over non-operative measures. These trends mirror those of subacromial decompression and rotator cuff repair of the shoulder, again in the absence of robust evidence to demonstrate clinical effectiveness. ${ }^{22}$ Increasing questions are also being raised over the efficacy of arthroscopic knee surgery. ${ }^{18}$

The rate of increase in the number of arthroscopic hip procedures is broadly in line with that reported in 
Table 3 Regional variation in arthroscopic hip procedures in England per 100000 population

\begin{tabular}{lllllllllllll}
\hline & $\mathbf{2 0 0 2}$ & $\mathbf{2 0 0 3}$ & $\mathbf{2 0 0 4}$ & $\mathbf{2 0 0 5}$ & $\mathbf{2 0 0 6}$ & $\mathbf{2 0 0 7}$ & $\mathbf{2 0 0 8}$ & $\mathbf{2 0 0 9}$ & $\mathbf{2 0 1 0}$ & $\mathbf{2 0 1 1}$ & $\mathbf{2 0 1 2}$ & $\mathbf{2 0 1 3}$ \\
\hline North & 0.51 & 0.53 & 0.43 & 0.54 & 0.53 & 0.83 & 1.29 & 2.10 & 2.68 & 3.19 & 3.00 & 4.40 \\
Midlands & 0.55 & 0.64 & 0.93 & 1.03 & 1.42 & 1.27 & 1.47 & 1.73 & 2.21 & 2.22 & 1.83 & 2.50 \\
London & 0.34 & 0.34 & 0.52 & 0.51 & 0.83 & 0.67 & 1.36 & 1.66 & 2.03 & 2.18 & 2.50 & 2.30 \\
South East & 0.58 & 0.81 & 0.97 & 1.37 & 1.79 & 1.70 & 2.38 & 2.97 & 4.07 & 4.03 & 5.55 & 5.34 \\
South West & 0.50 & 0.58 & 0.67 & 1.09 & 1.05 & 1.05 & 1.65 & 2.28 & 4.25 & 5.24 & 6.75 & 8.63 \\
England & 0.51 & 0.59 & 0.71 & 0.87 & 1.10 & 1.10 & 1.57 & 2.08 & 2.82 & 3.09 & 3.36 & 4.09 \\
\hline
\end{tabular}

the USA where a $365 \%$ increase was reported between 2004 and $2009^{15}$ and a $250 \%$ increase between 2007 and $2011 .^{16}$ The incidence of hip arthroscopy reported in Korea is comparable to that in England at 5.17 per 100000 in $2010 .{ }^{14}$ Studies from the USA have calculated procedure incidence using the PearlDiver Patient Records Database and hence are not representative of the general population. Our study underestimates the number of hip arthroscopy procedures performed in England since it does not include those undertaken in private healthcare.

Several factors are likely to be driving the increasing number of hip arthroscopies. Conditions such as femoracetabular impingement and labral tears are increasingly recognised as a source of pain and future osteoarthritis ${ }^{23}$ by both clinicians and patients. Demands are buoyed by outcomes from cohort studies, which report good shortterm and medium-term outcomes for a wide range of arthroscopic hip procedures. ${ }^{24} 25$ Guidance from the National Institute for Health and Clinical Excellence (NICE) may have played a role. In 2007, NICE highlighted the uncertain efficacy of hip arthroscopy for the treatment of femoracetabular impingement, whereas in 2011, they concluded that there was adequate evidence

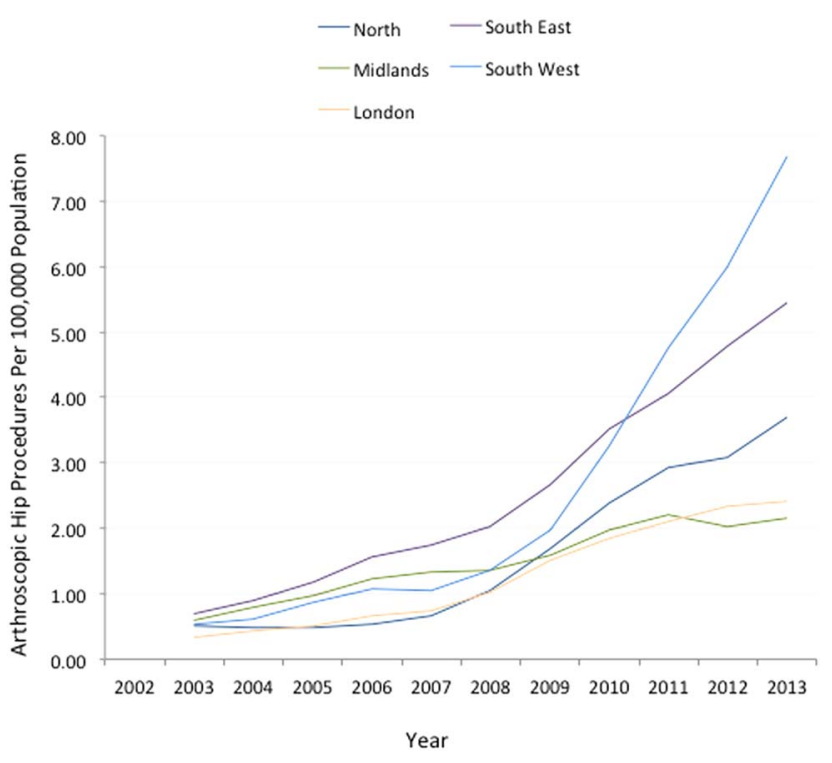

Figure 3 Regional variation in arthroscopic hip procedures in England per 100000 population represented as a non-weighted moving average over 2 years. of symptom improvement in the short and medium term. There is no strong inflection of the trend line at these time points and it is not possible to say with any certainty that they influenced practice. In the USA, there was an 18-fold increase in the number of hip arthroscopies performed by candidates of the American Board of Orthopaedic Surgery between 1999 and 2009 ${ }^{11}$ and a $600 \%$ increase between 2006 and 2010. ${ }^{26}$ Hip arthroscopy is now an established procedure within training programmes.

Hip arthroscopy is more frequently performed in females $(60.3 \%)$ than in males $(39.7 \%)$ in England and this has not changed during the period of study. The same gender ratio was reported in the USA where $63 \%$ patients are female. ${ }^{16}$ Additional studies from the USA and Korea have reported more equal gender distributions with females representing $52.9 \%^{15}$ and $51.9 \%{ }^{14}$ respectively. The higher number of procedures in females is an interesting finding given FAI, one of the most frequent indications for hip arthroscopy, ${ }^{16}$ has a higher prevalence in males. ${ }^{27}$ The HES database does not utilise sufficiently specific codes to explore the indications for surgery or the nature of procedure performed, and this is an area for future research. There are likely to be gender-specific indications for arthroscopic hip surgery.

Median age at hip arthroscopy is 40-44 years for females and 35-39 years for males, although there is no statistically significant difference in age. These ages are comparable to studies in the USA, ${ }^{15}$ and slightly younger than a study from Korea. ${ }^{14}$ In the USA, the greatest increase in the number of procedures was seen in patients $<30$ years of age, ${ }^{16}$ as is the case in our study. This may relate to the publication of good outcomes in active young adults who are able to return to high level sporting activities. ${ }^{28}$ Conversely, outcomes are worse in older patients. ${ }^{29}$

There is significant regional variation in the incidence of hip arthroscopy in England with continuing divergence. The highest incidence is seen in the Southwest and the lowest is in East Midlands. Regional variation is also seen in the USA, albeit less pronounced with a 2.05-fold difference between regions ${ }^{15}$ compared with the 6.69-fold difference in this study. Key factors are likely to be local expertise in hip arthroscopy and the local commissioning of services in England. Hip arthroscopy is not funded by the NHS in many regions given 
Figure 4 Regional variation in number of hip arthroscopy procedures per 100000 population in each strategic health authority region 2002-2013.
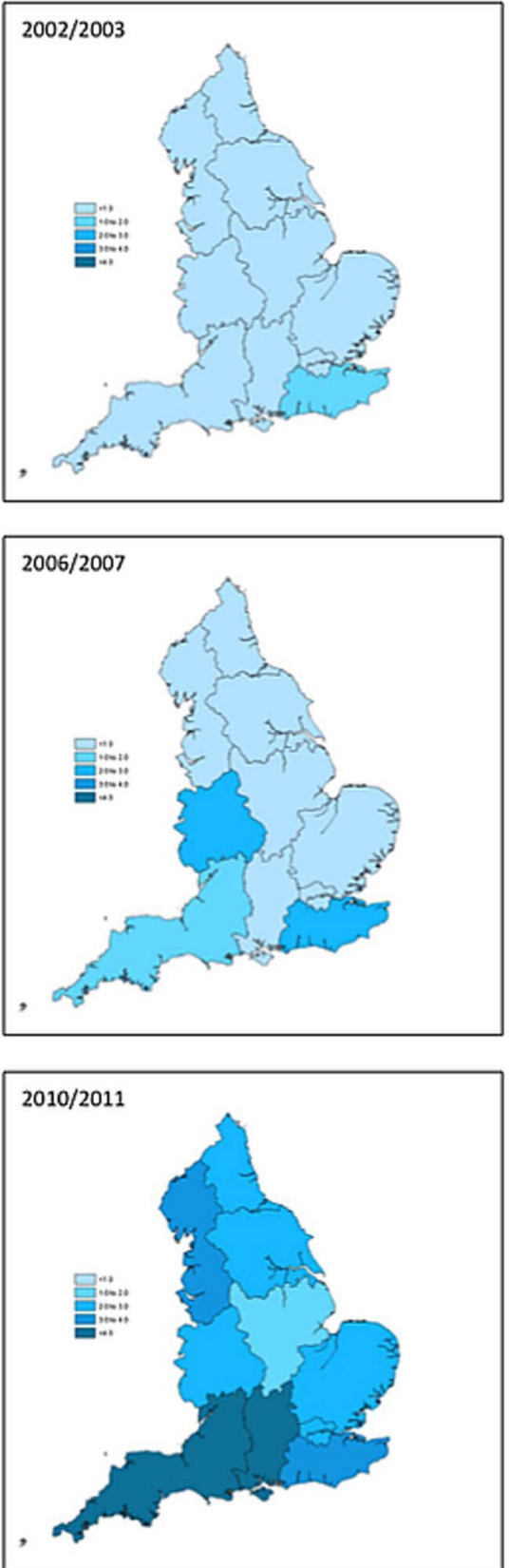
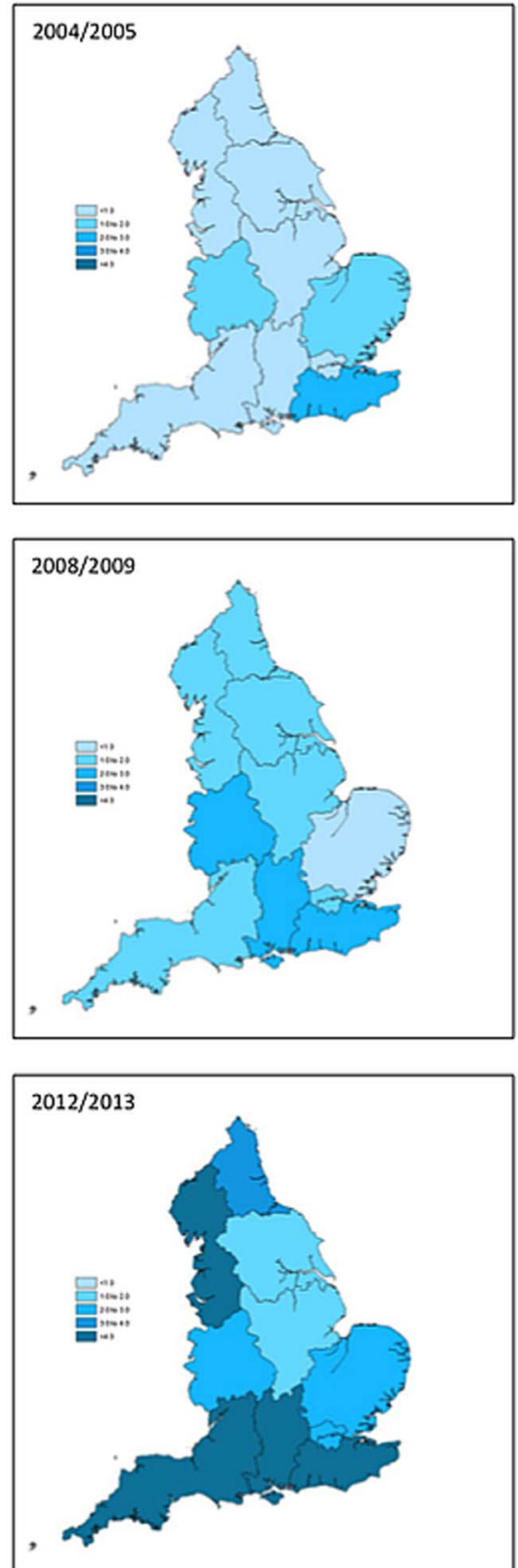

the limited evidence of efficacy available for many arthroscopic hip procedures. Indeed, equipoise is present within surgeon and patient communities for the arthroscopic treatment of FAI. ${ }^{19}$ Results from robust clinical trials will inform decision makers and may give rise to more standardised care.

Our forecast rise in the number of arthroscopic hip procedures of $1388 \%$ between 2002 and 2023 will accentuate challenging funding decisions within the NHS. It is difficult to quantify the cost of hip arthroscopy procedures due to their heterogeneous nature. A study from America estimated an average direct cost of $\$ 11850$ for arthroscopic treatment of femoroacetabular impingement and concluded that this was cost-effective in patients without evidence of osteoarthritis at $\$ 21700$ per Quality Adjusted Life Year (QALY). ${ }^{30}$ These results were replicated in a study from Scotland with an estimated a cost of $£ 19335$ per QALY, meeting the NICE threshold for cost-effective inventions. ${ }^{31}$ Cost-analysis is required for the diverse spectrum of hip conditions treated arthroscopically.

There are several limitations to this study. As already discussed, limitations of the HES database are the exclusion of procedures performed within private healthcare sector and the limited codes available to determine the precise indication and nature of procedure performed. Inclusion of new OPCS-4 codes for specific diagnoses and arthroscopic hip procedures would greatly facilitate the study of clinical activities. At present it is not possible to accurately code the array of different procedures performed. The three most frequently used codes in the final year of this study were 'endoscopic excision of 
articular cartilage', 'endoscopic decompression of joint' and 'other endoscopic therapeutic procedure'.

It is clear that the number of arthroscopic procedures continues to increase in line with observations from the USA and Korea. Robust evidence of efficacy is required from clinical studies and research priorities should reflect the changing nature of healthcare provision. An increasing demand for hip arthroscopy may also have implications for physiotherapy rehabilitation and orthopaedic training, and this is particularly salient given the procedure has a very steep learning curve. ${ }^{32}$

Acknowledgements The authors would like to acknowledge support from the National Institute for Health Research (NIHR) Oxford Musculoskeletal Biomedical Research Unit.

Contributors AJRP was responsible for study conception and design, acquisition of data, analysis and interpretation of data, drafting and critical revision of manuscript. TTM and JB were responsible for analysis and interpretation of data, drafting and critical revision of manuscript. $\mathrm{JH}, \mathrm{LM}$ and $\mathrm{KW}$ were responsible for acquisition of data, analysis and interpretation of data. GERT, AT and AJA were responsible for drafting and critical revision of manuscript. GC was responsible for analysis, interpretation of data and statistical support. AJC was responsible for study conception and design, analysis and interpretation of data, drafting and critical revision of manuscript. SG-J was responsible for study conception and design, analysis and interpretation of data, drafting and critical revision of manuscript.

Funding AJRP received funding from a Joint Royal College of Surgeons of England and Dunhill Medical Trust Research Fellowship. JB received funding from a Royal College of Surgeons of England Research Fellowship.

Competing interests None declared.

Provenance and peer review Not commissioned; externally peer reviewed.

Open Access This is an Open Access article distributed in accordance with the Creative Commons Attribution Non Commercial (CC BY-NC 4.0) license, which permits others to distribute, remix, adapt, build upon this work noncommercially, and license their derivative works on different terms, provided the original work is properly cited and the use is non-commercial. See: http:// creativecommons.org/licenses/by-nc/4.0/

\section{REFERENCES}

1. Nusem I, Jabur MK, Playford EG. Arthroscopic treatment of septic arthritis of the hip. Arthroscopy 2006;22:902.e1-3.

2. Park MS, Yoon SJ, Choi SM. Arthroscopic reduction and internal fixation of femoral head fractures. J Orthop Trauma 2014;28:e164-8.

3. Larson CM, Stone RM. Current concepts and trends for operative treatment of FAl: hip arthroscopy. Curr Rev Musculoskelet Med 2013;6:242-9.

4. Haviv B, O'Donnell J. Arthroscopic treatment for acetabular labral tears of the hip without bony dysmorphism. Am J Sports Med 2011;39(Suppl):79S-84S.

5. El Bitar YF, Lindner D, Jackson TJ, et al. Joint-preserving surgical options for management of chondral injuries of the hip. J Am Acad Orthop Surg 2014;22:46-56.

6. Shindle MK, Ranawat AS, Kelly BT. Diagnosis and management of traumatic and atraumatic hip instability in the athletic patient. Clin Sports Med 2006;25:309-26, ix-x.

7. Boyer T, Dorfmann H. Arthroscopy in primary synovial chondromatosis of the hip: description and outcome of treatment. $J$ Bone Joint Surg Br 2008;90:314-18.

8. de SA D, Phillips M, Philippon MJ, et al. Ligamentum teres injuries of the hip: a systematic review examining surgical indications, treatment options, and outcomes. Arthroscopy 2014;30:1634-41.
9. Eberhardt O, Fernandez FF, Wirth T. Arthroscopic reduction of the dislocated hip in infants. J Bone Joint Surg Br 2012;94:842-7.

10. Ilizaliturri VM Jr, Camacho-Galindo J. Endoscopic treatment of snapping hips, iliotibial band, and iliopsoas tendon. Sports Med Arthrosc 2010;18:120-7.

11. Colvin AC, Harrast J, Harner C. Trends in hip arthroscopy. J Bone Joint Surg Am 2012;94:e23.

12. Glick JM, Sampson TG, Gordon RB, et al. Hip arthroscopy by the lateral approach. Arthroscopy 1987;3:4-12.

13. Matsuda DK, Carlisle JC, Arthurs SC, et al. Comparative systematic review of the open dislocation, mini-open, and arthroscopic surgeries for femoroacetabular impingement. Arthroscopy 2011;27:252-69.

14. Lee YK, Ha YC, Yoon BH, et al. National trends of hip arthroscopy in Korea. J Korean Med Sci 2014;29:277-80.

15. Montgomery SR, Ngo SS, Hobson T, et al. Trends and demographics in hip arthroscopy in the United States. Arthroscopy 2013:29:661-5.

16. Sing DC, Feeley BT, Tay B, et al. Age-related trends in hip arthroscopy: a large cross-sectional analysis. Arthroscopy 2015;31:2307-13.e2.

17. Millennium Research Group. Hip Arthroscopy Procedures To Soar Through 2013. 2009. 10.07.2013. http://mrg.net/News-and-Events/ Press-Releases/HIP-ARTHROSCOPY-PROCEDURES-TO-SOARTHROUGH-2013.aspx

18. Carr A. Arthroscopic surgery for degenerative knee. BMJ 2015;350: h2983.

19. Palmer AJ, Thomas GE, Pollard TC, et al. The feasibility of performing a randomised controlled trial for femoroacetabular impingement surgery. Bone Joint Res 2013;2:33-40.

20. Palmer AJ, Ayyar-Gupta V, Dutton SJ, et al. Protocol for the Femoroacetabular Impingement Trial (FAIT): a multi-centre randomised controlled trial comparing surgical and non-surgical management of femoroacetabular impingement. Bone Joint Res 2014;3:321-7

21. Health \& Social Care Information Centre. Hospital Episode Statistics Database. http://www.hscic.gov.uk/hes

22. Judge A, Murphy RJ, Maxwell R, et al. Temporal trends and geographical variation in the use of subacromial decompression and rotator cuff repair of the shoulder in England. Bone Joint $J$ 2014;96-B:70-4

23. Agricola R, Heijboer MP, Bierma-Zeinstra SM, et al. Cam impingement causes osteoarthritis of the hip: a nationwide prospective cohort study (CHECK). Ann Rheum Dis 2013;72:918-23.

24. Kemp JL, Collins NJ, Makdissi M, et al. Hip arthroscopy for intra-articular pathology: a systematic review of outcomes with and without femoral osteoplasty. Br J Sports Med 2012;46:632-43.

25. de Sa D, Alradwan H, Cargnelli S, et al. Extra-articular hip impingement: a systematic review examining operative treatment of psoas, subspine, ischiofemoral, and greater trochanteric/pelvic impingement. Arthroscopy 2014;30:1026-41.

26. Bozic KJ, Chan V, Valone FH, et al. Trends in hip arthroscopy utilization in the United States. J Arthroplasty 2013;28(8 Suppl):140-3.

27. Laborie LB, Lehmann TG, Engesæter IØ, et al. Prevalence of radiographic findings thought to be associated with femoroacetabular impingement in a population-based cohort of 2081 healthy young adults. Radiology 2011;260:494-502.

28. Philippon M, Schenker M, Briggs K, et al. Femoroacetabular impingement in 45 professional athletes: associated pathologies and return to sport following arthroscopic decompression. Knee Surg Sports Traumatol Arthrosc 2007;15:908-14.

29. McCarthy JC, Jarrett BT, Ojeifo O, et al. What factors influence long-term survivorship after hip arthroscopy? Clin Orthop Relat Res 2011;469:362-71.

30. Shearer DW, Kramer J, Bozic KJ, et al. Is hip arthroscopy cost-effective for femoroacetabular impingement? Clin Orthop Relat Res 2012;470:1079-89.

31. Clement ND, MacDonald D, Gaston P. Hip arthroscopy for femoroacetabular impingement: a health economic analysis. Hip Int 2014;24:457-64.

32. Hoppe DJ, de Sa D, Simunovic N, et al. The learning curve for hip arthroscopy: a systematic review. Arthroscopy 2014;30:389-97. 